\title{
Study the Static Adsorption/Desorption of Formaldehyde on
}

\section{Activated Carbons}

\author{
Chunlan Lu ${ }^{\mathrm{a}}$, , Liwei Pan ${ }^{\mathrm{b}}$ and Bo Zhu ${ }^{\mathrm{c}}$ \\ College of Environmental and Chemical Engineering, Dalian University \\ Dalian 116622, China \\ aemail: Iclsophia@163.com, bemail: panliwei@dlu.edu.cn, cemail: zhubo@dl.cn
}

\begin{abstract}
Keywords: activated carbon; Formaldehyde; adsorption; desorption; pore structure
Abstract. Three commercial wood activated carbons for air purification were selected for static adsorption/desorption of formaldehyde. The influence of the pore structure, surface functional groups and particle size of the activated carbon on the static adsorption of formaldehyde, and temperature on the desorption were researched. The results show that surface functional groups of the three activated carbons are basically the same, have less effect on the adsorption of formaldehyde; approximate BET surface area, larger microporosity of activated carbon adsorption capacity of formaldehyde is larger; at the same condition, the smaller particle size of activated carbon, adsorption capacity of formaldehyde is larger; temperature is one of the key factor effect on formaldehyde desorption, the absorption equilibrium activated carbon desorption should be at not lower than $70^{\circ} \mathrm{C}$.
\end{abstract}

\section{Introduction}

Indoor air quality problems have become of serious environmental concern[1]. Formaldehyde is one of the most common pollutants present in indoor air, as it is emitted from various building materials including furniture and household products. Formaldehyde causes sneezing and coughing, and leads to acute poisoning, dermal allergies and allergic asthma; therefore, the World Health Organization has recommended a short-term guideline of $0.1 \mathrm{mg} / \mathrm{m}^{3}$ for a $30 \mathrm{~min}$ exposure to prevent sensory irritation in the general population [2]. As a result, appropriate air treatment technologies need to be applied for the effective control of formaldehyde in indoor air.

Adsorption using activated carbon is one of the most common methods for the removal of formaldehyde at low concentrations in indoor air. The activated carbon is characterized by a strong adsorption capacity which is attributed to its large internal surface area, porosity, and high degree of surface reactivity [3]. To enhance the adsorptive capacity of activated carbon for formaldehyde, activated carbon have been surface modified using amino groups[4], photo-catalysts [5] or silver catalysts[6], which have been shown to be effective methods when used in series with activated carbon, but the combined process still needs to be improved to achieve high and reliable formaldehyde removals.

For most people, don't know how to choose the suitable activated carbon, as well as how to make full use of the properties of activated carbon for indoor air purification. In this paper, three commercial activated carbons derived from coconut shell, wood and apricot shell as adsorbent to remove formaldehyde. The influence of the pore structure, surface functional groups and particle size of the activated carbon on the static adsorption of formaldehyde, and temperature on the desorption were researched.

\section{Materials and methods}

Materials. Three commercial activated carbons derived from coconut shell, wood and apricot shell, respectively labeled $\mathrm{AC} 1, \mathrm{AC} 2$ and $\mathrm{AC} 3$. The reagents used for the experiment: formaldehyde (purity $30-40 \%)$. 
Characteristics. BET specific surface area and pore volume of the samples were determined by the nitrogen adsorption -desorption isotherms measured by Gas Sorption Analyzer (Quantachrome Corp., NOVA-4000 e) at77 K. The specific surface areas were calculated using BET equation. In addition, $\mathrm{DA}$ method to calculate the micropore volume and average pore diameter, the relative pressure $\mathrm{P} / \mathrm{P} 0=$ 0.99 when nitrogen adsorption quantity calculation of the total pore volume, DFT method to calculate pore size distribution.

The surface functional groups of activated carbon were analyzed by an infrared spectrometer (Nicolet Magna - IR550) using the KBr pallet. The spectra were measured from 4000 to $400 \mathrm{~cm}^{-1}$.

Adsorption/desorption of formaldehyde. The activated carbon weighed in the weighing bottle, and dried at $130^{\circ} \mathrm{C}$ for two hours, then cooling down to room temperature covered. The weighing bottles uncovered were put into desiccators with thin layer formaldehyde at the bottom, began to adsorption at room temperature, and were weighed interval, until activated carbon weight no longer increases. In addition, activated carbons grinding after screening 40-100 mesh (AC-40) and 200 mesh (AC-200) were also studied for formaldehyde adsorption. The adsorption equilibrium activated carbon, desorption at $30^{\circ} \mathrm{C}, 50{ }^{\circ} \mathrm{C}, 70^{\circ} \mathrm{C}$ and $80{ }^{\circ} \mathrm{C}$, respectively, weighted every 30 minutes, until the weight no change to stop the test.

\section{Results and discussion}

The pore structure of activated carbon. $\mathrm{N}_{2}$ adsorption/desorption isotherms at $77 \mathrm{~K}$ of the activated carbons are shown in Fig.1. According to the IUPAC physical adsorption isotherm classification, AC1 exhibited type I isotherms, and no obvious hysteresis loop, the adsorption quantity, with the increase of $\mathrm{P} / \mathrm{P}_{0}$ and rapid growth, the microporous activated plays a main role; And then the adsorption quantity increases flattens out, closes to the horizontal platform, shows that micropore is filled, and almost no further adsorption occurs. AC2 exhibited typell isotherms, and hysteresis loop classification belongs to the $\mathrm{H} 4$, in the region of the low relative pressure, gas adsorption has a rapid growth, this is a result of the micropore filling, then slowly rising, indicating mesopore and macropore of the multilayer adsorption, and condensation occur inside the pore in the $\mathrm{N}_{2}$ adsorption/desorption. AC3 adsorption quantity is small, show less pore structure.

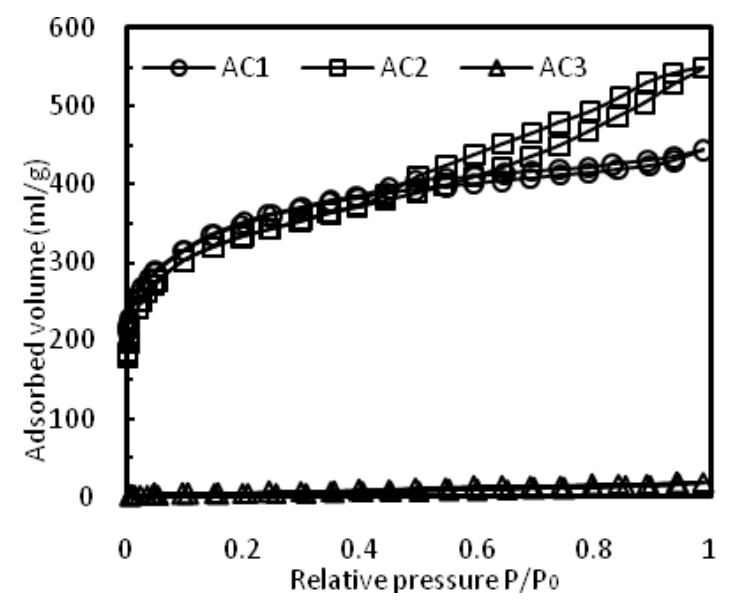

Fig. $1 \mathrm{~N}_{2}$ adsorption/desorption isotherms at $77 \mathrm{~K}$ for activated carbons

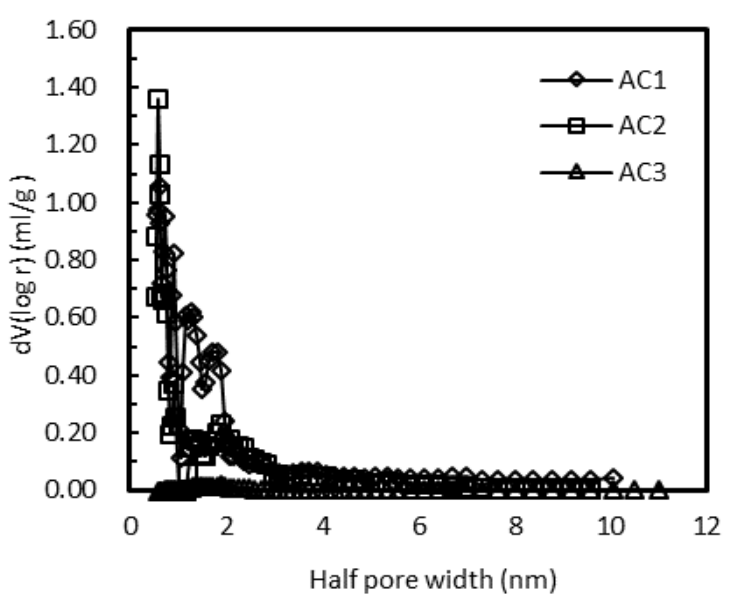

Fig.2 Pore size distributions of activated carbons

Pore size distribution of the active carbons are shown in Fig.2, mainly microporous in the activated carbons, most of the pore diameter are smaller than $2 \mathrm{~nm}$. The structural parameters calculated from nitrogen isotherms are listed in Table 1, shows that although the total pore volume and pore volume of $\mathrm{AC} 2$ is the largest, but its micropore volume rate is less than $\mathrm{AC} 1$, and average pore diameter is larger than the AC1. 
Table 1 Pore structure parameters of activated carbons

\begin{tabular}{cccccc}
\hline Samples & $\mathrm{S}_{\mathrm{BET}}\left(\mathrm{m}^{2} / \mathrm{g}\right)$ & $\mathrm{V}_{\text {Total }}(\mathrm{ml} / \mathrm{g})$ & $\mathrm{V}_{\text {Micro }}(\mathrm{ml} / \mathrm{g})$ & $\mathrm{V}_{\text {Micro }}(\%)$ & $\mathrm{D}_{\text {Ave }}(\mathrm{nm})$ \\
\hline $\mathrm{AC} 1$ & 1082 & 0.69 & 0.66 & 96 & 0.75 \\
$\mathrm{AC} 2$ & 1036 & 0.85 & 0.71 & 84 & 0.82 \\
$\mathrm{AC} 3$ & 18 & 0.03 & 0.02 & 59 & 1.13 \\
\hline
\end{tabular}

Surface functional groups of activated carbon. Fig.3 shows IR spectra of the three commercial activated carbons. All spectra show a wide absorption band at $3200 \sim 3600 \mathrm{~cm}^{-1}$ with a maximum at $3420 \sim 3440 \mathrm{~cm}^{-1}$. This band can be assigned to the $\mathrm{O}-\mathrm{H}$ stretching mode of hydroxyl groups and adsorbed water[7]. The band at $1500 \sim 1600 \mathrm{~cm}^{-1}$ due to $\mathrm{C}=\mathrm{C}$ aromatic ring stretching vibration [8]. Broad bands at $1000 \sim 1300 \mathrm{~cm}^{-1}$ have been assigned to $\mathrm{C}-\mathrm{O}$ stretching vibration in phenolic hydroxyl or hydrocarbon hydroxyl. The AC3 shows very small peaks at in $2900 \sim 2800 \mathrm{~cm}^{-1}$ and $1450 \mathrm{~cm}^{-1}$, suggests this sample contain a small amount of carboxyl groups.

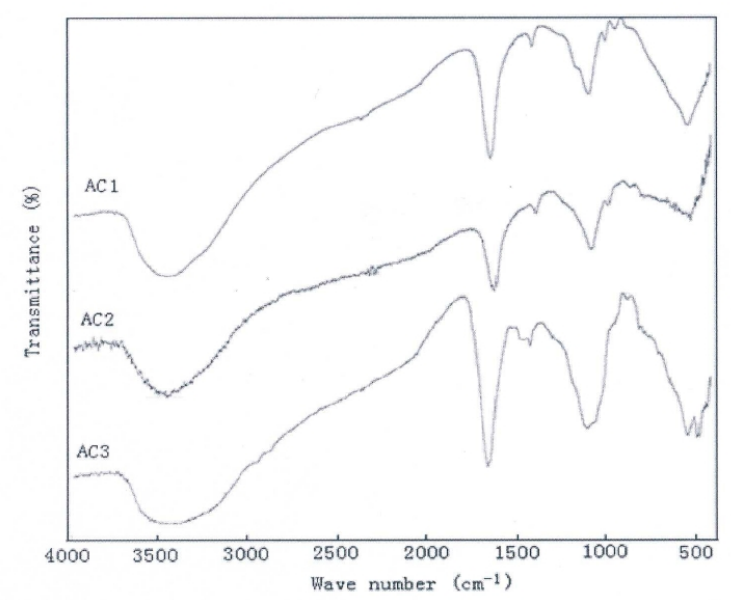

Fig.3 IR spectrums of activated carbons

Static adsorption of formaldehyde on activated carbon. Fig. 4 shows the static formaldehyde adsorption curve of activated carbons. The adsorption capacity of the three activated carbons are obviously difference, the equilibrium absorption capacity of $\mathrm{AC} 1$ is highest, more than $0.6 \mathrm{~g} / \mathrm{g}$; AC3 equilibrium absorption capacity is less than $0.2 \mathrm{~g} / \mathrm{g}$. Formaldehyde adsorption capacity of AC1 increases rapidly over time at the beginning, then increases flattens out after 24 hours, close to the horizontal platform after 96 hours; the adsorption capacity of AC2 and AC3 basic does not increase after 24 hours, indicates reaching adsorption equilibrium of formaldehyde. Associated with pore structure parameters of activated carbons (table 1), AC1 and AC2 with similar BET specific surface area, but the microporosity of AC1 (96\%) is higher than that of AC2 (84\%), indicating the formaldehyde adsorption ability is mainly depended on the microporosity of activated carbon.

Fig.5 illustrates the different particle size of activated carbons effect on the adsorption capacity of formaldehyde. It can be seen from Fig.5, particle size 200 mesh of AC1 and AC2 adsorption quantity of formaldehyde are all higher than that of 40-100 mesh about $0.10 \mathrm{~g} / \mathrm{g}$; AC3 adsorption capacity is small, shows no obvious change. At the same condition, the smaller the particle size of activated carbon, the 
larger adsorption capacity of formaldehyde. The activated carbon is broken into small particles by grinding, increased external surface area, without changes the inside pore structure of the activated carbon, shows that the external surface of the activated carbon can also adsorption formaldehyde.

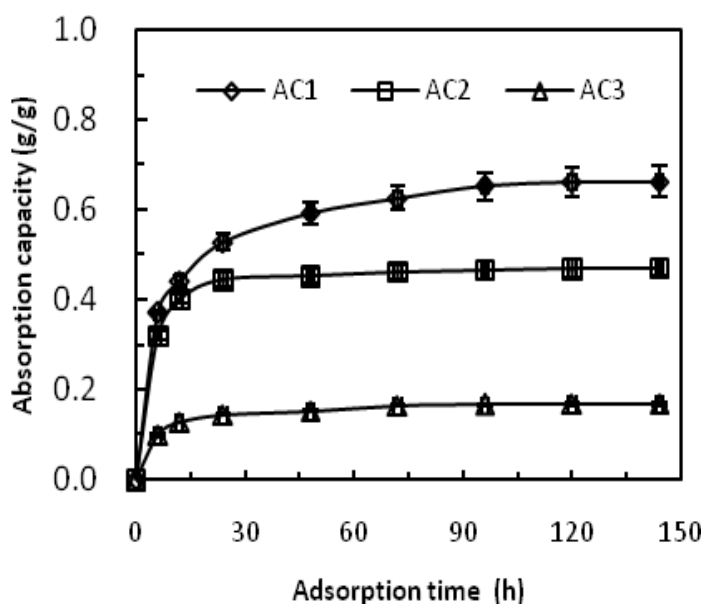

Fig.4 Formaldehyde adsorption curves for activated carbons

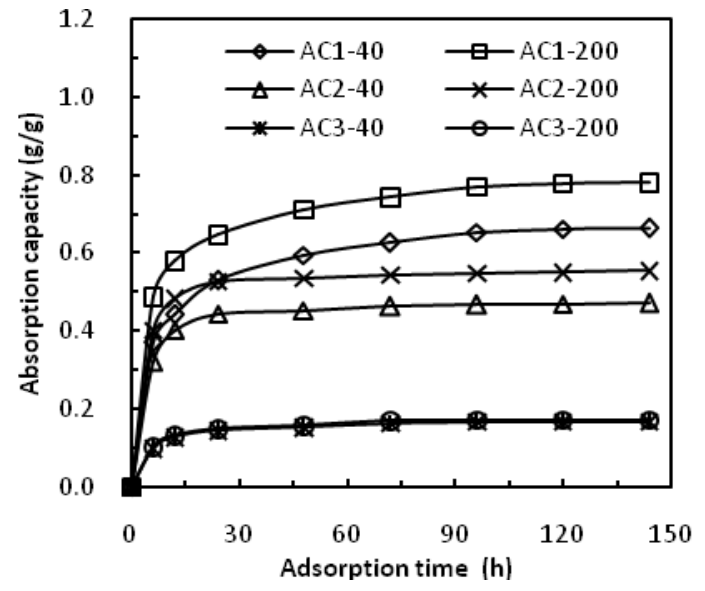

Fig.5 Formaldehyde adsorption curves for different particle size activated carbons

Desorption of formaldehyde on activated carbon. The desorption curves respectively at $30^{\circ} \mathrm{C}, 50$ ${ }^{\circ} \mathrm{C}, 70{ }^{\circ} \mathrm{C}$ and $80^{\circ} \mathrm{C}$ of formaldehyde equilibrium adsorption of $\mathrm{AC} 1$ are shown in Fig.6. The desorption curves are almost the same trend, desorption is fast at the first 30 minutes, then is slow, finished basically after 150 minutes; desorption at $30^{\circ} \mathrm{C}$, about $5 \%$ of formaldehyde residue; desorption at $30^{\circ} \mathrm{C}$, about $3 \%$ of formaldehyde residue; desorption at $70{ }^{\circ} \mathrm{C}$ and $80{ }^{\circ} \mathrm{C}$ only remaining about $0.3 \%$ of formaldehyde. Fig.7 shows the desorption curves of the three activated carbons with formaldehyde adsorption equilibrium at $80{ }^{\circ} \mathrm{C}$. The activated carbon formaldehyde desorption curves are similar, suggesting desorption are in the same rules. Therefore, formaldehyde equilibrium adsorption of activated carbon should be at least above $70{ }^{\circ} \mathrm{C}$ for desorption; and desorption time of 60 minutes is enough.

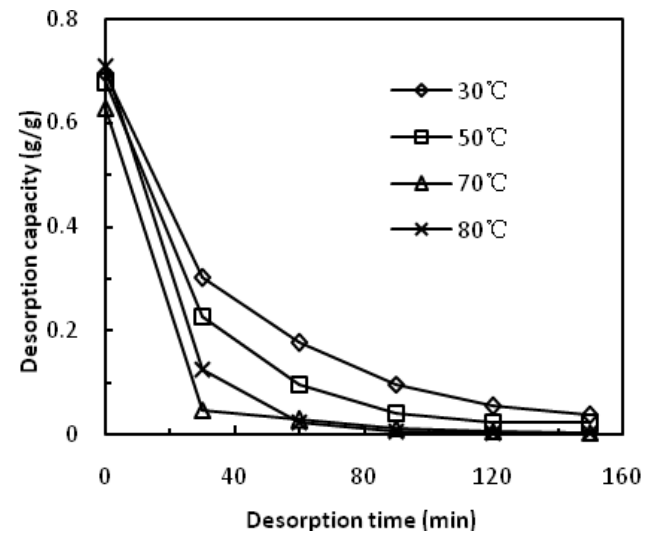

Fig.6 Formaldehyde desorption curves at different temperature for sample AC1

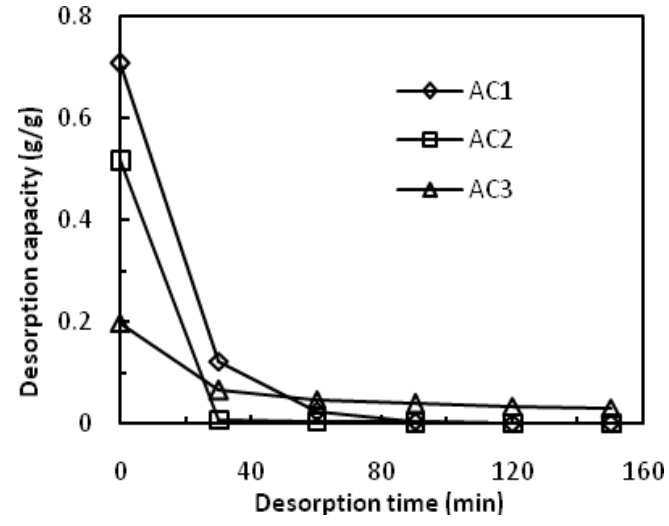

Fig.7 Formaldehyde desorption curves for activated carbons

\section{Conclusions}

This study was conducted to investigate three commercial activated carbons derived from coconut shell, wood and apricot shell as adsorbent to remove formaldehyde. The results show that the surface functional groups of activated carbons are basically the same, have less effect on the formaldehyde adsorption capacity; the larger microporosity of the activated carbon, the greater the adsorption quantity of formaldehyde; at the same condition, the smaller the particle size of activated carbon 
adsorption quantity of formaldehyde is larger; Desorption temperature is one of the key factors effect on formaldehyde desorption, the equilibrium absorption of activated carbon should be above $70{ }^{\circ} \mathrm{C}$ for desorption; and desorption time of 60 minutes is enough.

\section{References}

[1] Y.X. Li. Research Situation of Indoor Air Pollution Control Technology. Journal of Huangshi Institute of Technology. 26(2010)21-25(In Chinese )

[2] World Health Organization, WHO Guidelines for Indoor Air Quality: Selected Pollutants, WHO Regional Office of Europe, 2010.

[3] R. C. Bansal, J.B. Donnet, F.Stoeckli. "Activated Carbon," Chaps. 1 and 3. Dekker, New York, 1988.

[4] S. Tanada, N. Kawasaki, T. Nakamura, M. Araki, M. Isomura, Removal of formaldehyde by activated carbons containing amino groups, J. Colloid Interface Sci. 214 (1999) 106-108.

[5]Y.W. Lu, D.H. Wang, C.F. Ma, H.C. Yang. The effect of activated carbon adsorption on the photocatalytic removal of formaldehyde. Building and Environment. 45 (2010) 615-621

[6] S.K. Shin, JH Song.Modeling and simulations of the removal of formaldehyde using silver nano-particles attached to granular activated carbon. Journal of Hazardous Materials.194 (2011) 385-392

[7] J. Zawadzki. Infrared spectroscopy in surface chemistry of carbon. In: Thrower PA, editor, Chemistry and physics of carbon. New York: Marcel Dekker, 1989, 147-386.

[8] A.M. Puziy, O.I. Poddubnaya, A. Martínez-Alonso, et al. Synthetic carbons activated with phosphoric acid I. Surface chemistry and ion binding properties. Carbon. 40(2002) 1493-1505 